Vol 9, No 1 (2021) | ISSN 2153-5914 (online) | DOI 10.5195/contemp/2021.322

http://contemporaneity.pitt.edu

\title{
The Contingent Body
}

\author{
Sepideh Tajalizadeh Dashti
}

\begin{abstract}
About the Author
Sepideh Tajalizadeh Dashti is an emerging interdisciplinary artist who lives in Memphis, Tennessee. She received her MFA from Western University in London, Ontario, in 2020. She migrated from Iran to Canada in 2011, and has lived in the United States since August 2019. Her artistic practice is related to an exploration of her body through performance and video. Documented through photography and installation, her work enacts a continual engagement with the injustice and tyrannical politics of her homeland. Dashti is always rediscovering, reinventing, and reinterpreting her Iranian identity, which functions as a pivotal point of context in her work. She earned her BFA at the University of Waterloo in Waterloo, Ontario, Canada, where she was the recipient of various awards, including the Lynn Holmes Memorial Award and Curator's Choice Award. Dashti's work has been exhibited across Canada, including at the Photophobia Contemporary Moving Image Festival, at Hamilton Artists Inc., and in exhibitions at the University of British Columbia in Vancouver, Trinity Square Video in Toronto, the University of Western Ontario in London, and University of Waterloo in Waterloo. Her work has also been exhibited internationally at Modern Panic $X$ in United Kingdom and as part of the exhibition Art as Advocacy: Promoting Equity and Social Justice for Women in the United States.
\end{abstract}




\section{The Contingent Body}

\author{
Sepideh Tajalizadeh Dashti
}

My practice is body-centric; I reclaim my body through mediums of performance, video, photography, and installation. My work focuses on the traumatized female body and attempts to represent the body through abject form, in pain or a grotesque state. My work deals with the personal psychology of ambiguity as a multicultural individual. This sense of ambiguity, which derives from personal experiences with the differences between cultures, evokes an unsettledness that politicizes spaces and comes into consciousness through my oppression as a woman. To respond to this consciousness, I strive to explore the construction of women's identity through social expectations, politics, traditional culture, and conservative belief structures that shift between Middle-East and Western cultures. I am in close dialogue with my homeland and aim to address critical issues that have affected me, as a woman from Iran. Furthermore, I try to generate questions concerning the legacies of the phallocentric system's impact on contemporary sociocultural realities of female embodied subjectivity. I explore theories of nomadic subjects, radical relationality, and queer feminist durationality concerning the conceptual representation of the in-between state that I have intimately experienced. I believe that, representation is a crucial location of the struggle for any exploited and oppressed bodies asserting subjectivity. I explore my identity in the hope of calling oppressive authorities into question. Perhaps there is not much hope for a bright future where differences are recognized without eliminating the voices of others. But striving to make this future creates a hope to continue and endure.

Readers are encouraged to contact the artist for links and passwords to the videos due to their sensitive nature. Dashti can be reached at: stajaliz@uwo.ca 


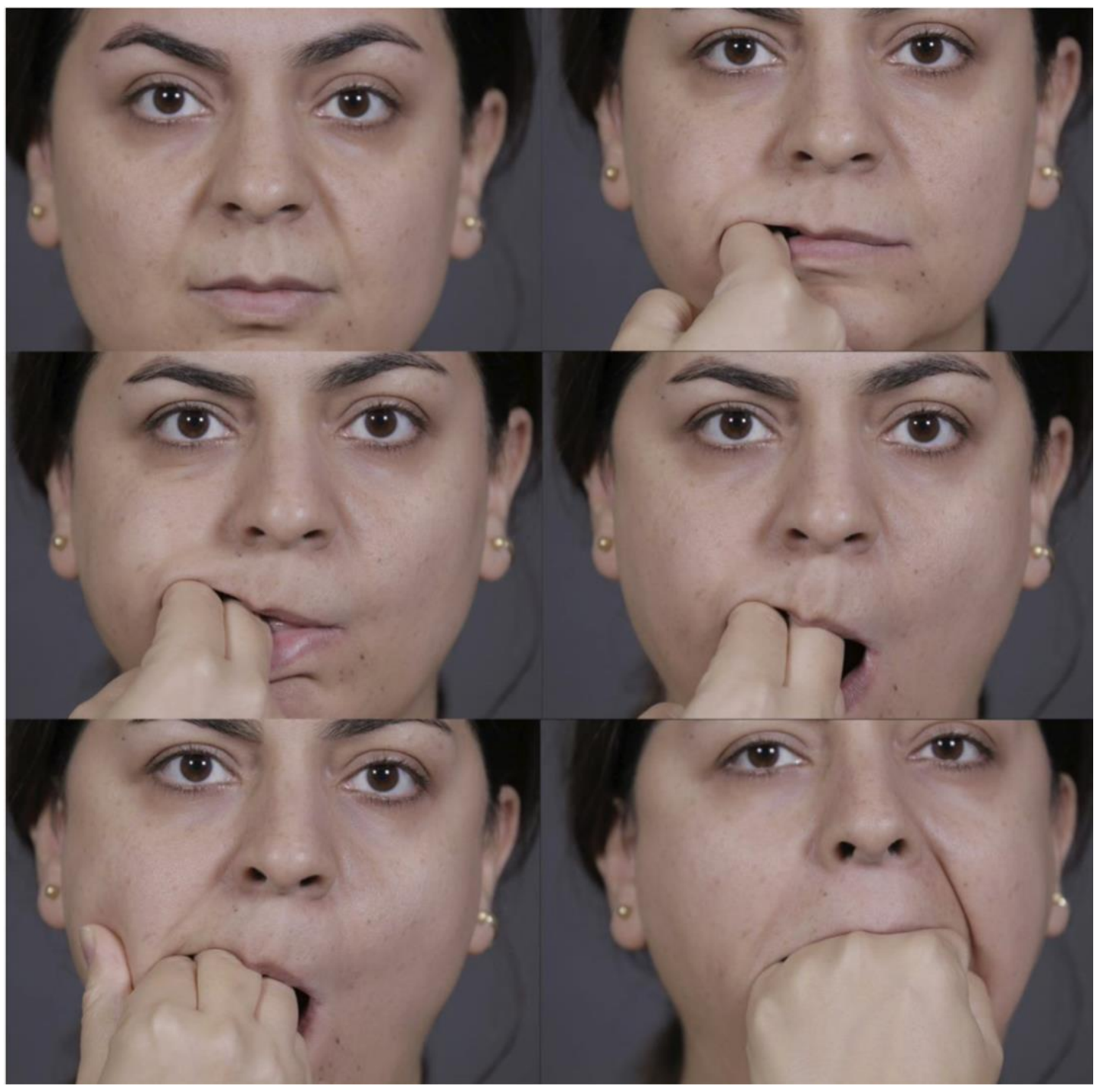

Figure 1

Sepideh Tajalizadeh Dashti, Don't Ask I Can't Sing, 2018. Film stills. 


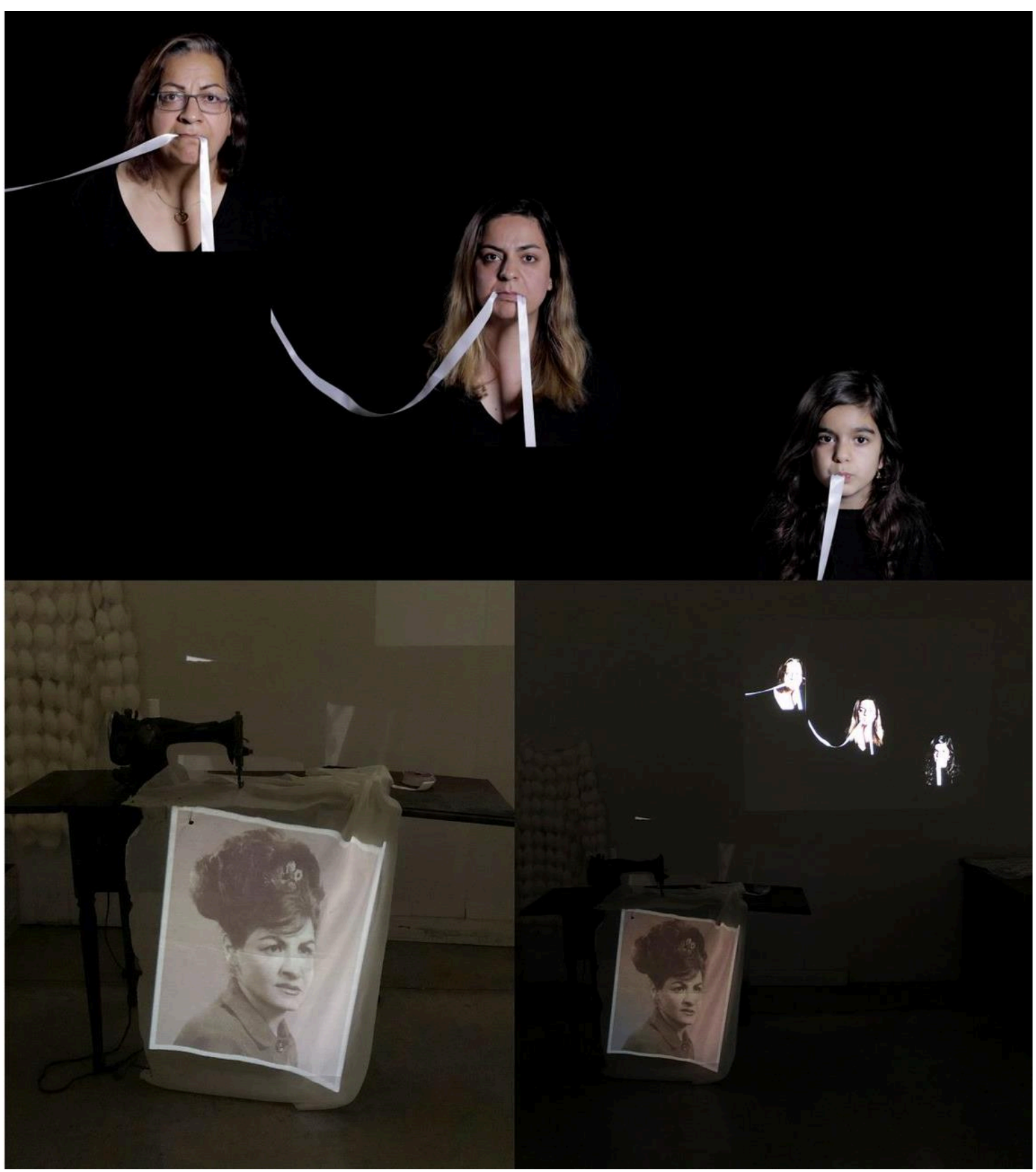

Figure 2

Sepideh Tajalizadeh Dashti, Generations, 2019. Installation (one channel video, projected photograph, sewing machine, fabric). 


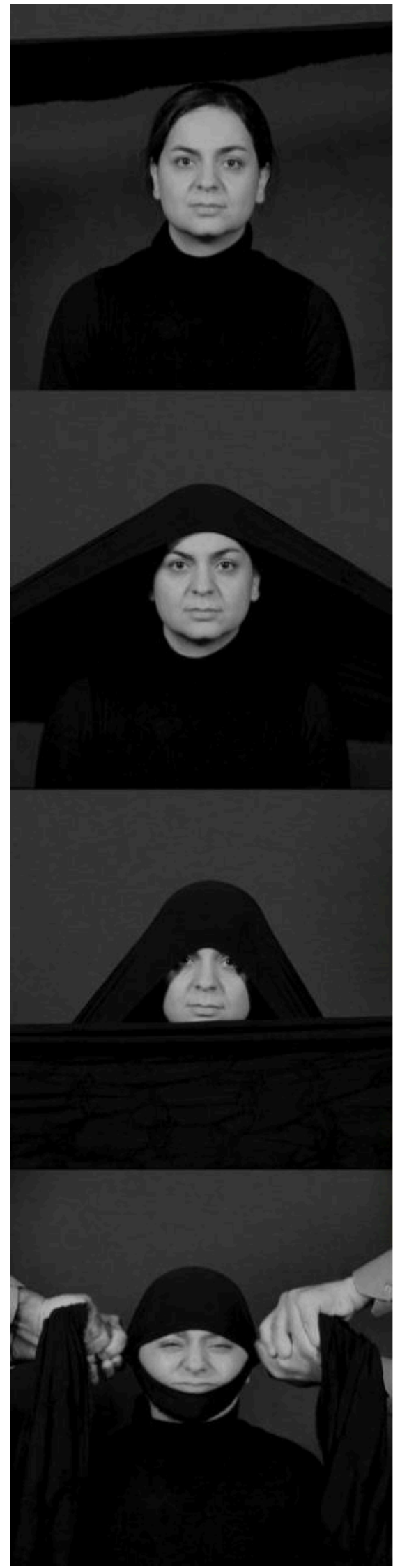

Figure 3

Sepideh Tajalizadeh Dashti, My Family Men, 2018. Film stills. 

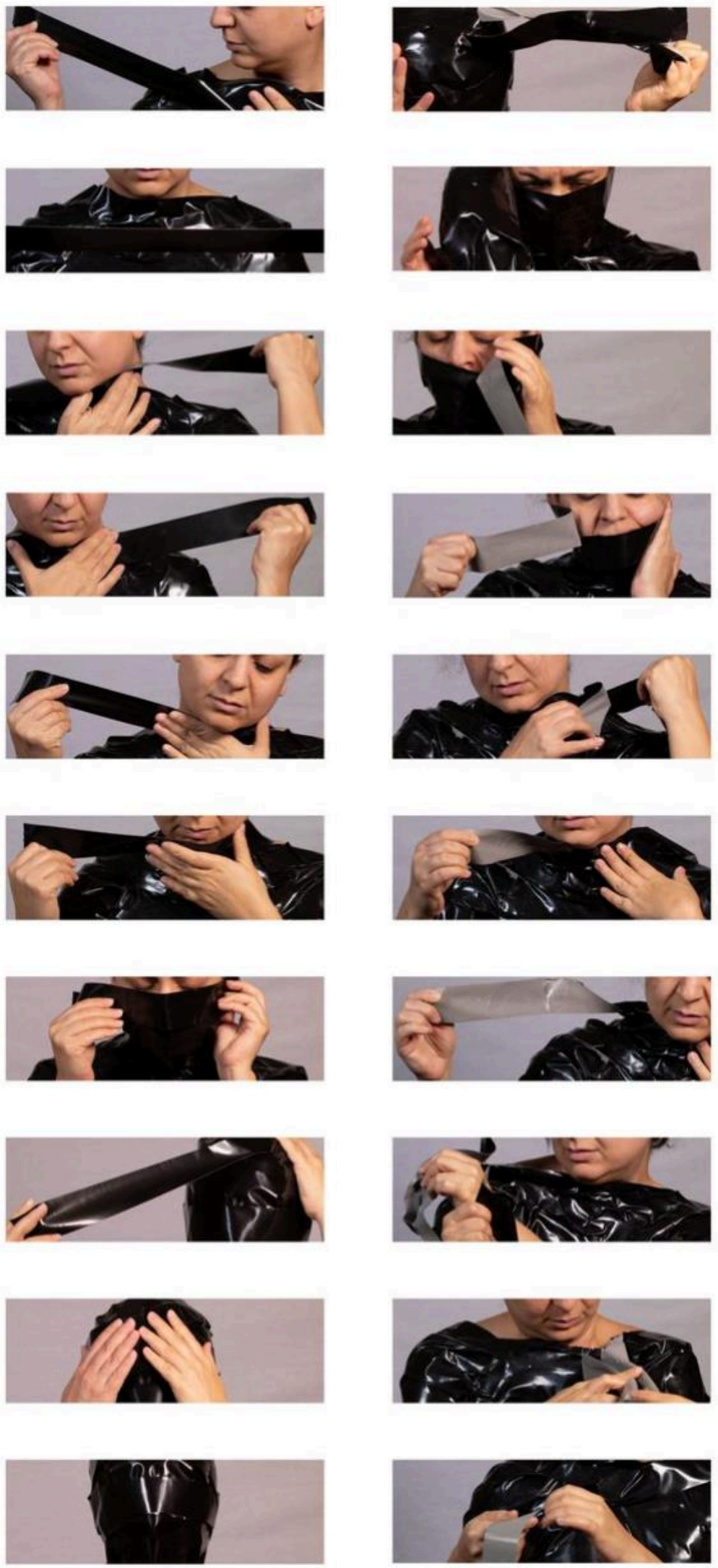
The naw directuess of the relation ship between otters and $\mathcal{L}$ is almost too much to handle. It is best not to speak unless they ark me a direct question. Ltry to think of it from their point of view. L tell myself it doesn't matter, but what $f$ tell nuyself is wrong. It does matter.

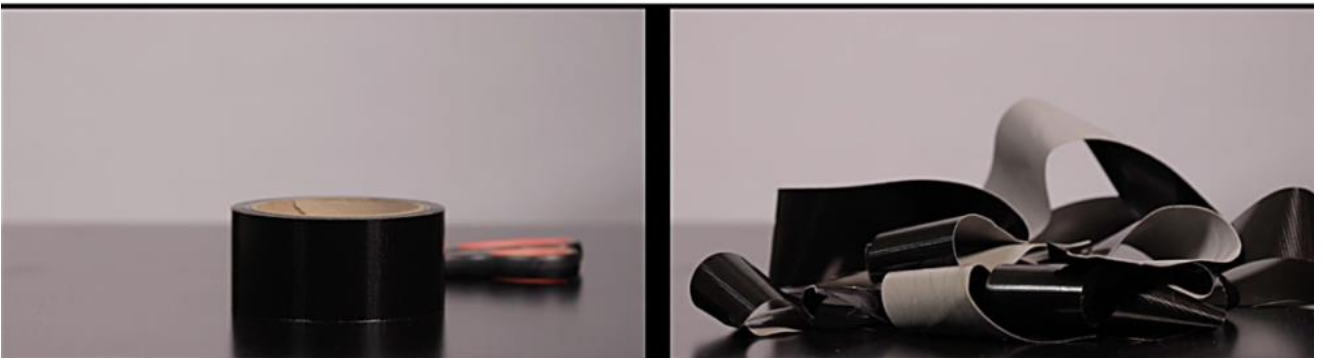

Figure 4

Sepideh Tajalizadeh Dashti, Untitled, 2019. Installation (two channel video, sound, photography). 
(cc)) EY New articles in this journal are licensed under a Creative Commons Attribution 4.0 United States License.

\section{ULLS D-Sonle}

This journal is operated by the University Library System of the University of Pittsburgh as part of its D-Scribe Digital Publishing Program, and is co-sponsored by the University of Pittsburgh Press. 